\title{
Prevalence of malaria in human population of district Killa Saifullah: Balochistan
}

Noor Jahan Umer and Muhammad Iqbal Yasinzai*

Department of Zoology University of Balochistan, Sariab Road, Quetta-Pakistan

*Corresponding author's email: Yasinzai_Iqbal@Yahoo.com

Citation

Noorjahan Umer and Muhammad Iqbal Yasinzai. Prevalence of malaria in human population of district Killa

Saifullah: Balochistan. Pure and Applied Biology. Vol. 6, Issue 4, pp1335-1339.

http://dx.doi.org/10.19045/bspab.2017.600143

Received: 16/06/2017 Revised: 04/10/2017

Accepted: 14/10/2017

Online First: 26/10/2017

\section{Abstract}

The present study was conducted to Examine the prevalence of Human malarial infection in Killa Saifullah district.A total No. of 4208 blood smear ware prepared twice in a month. in each locality The overall plasmodium mixed slide positivity rate was observed $20.0 \%$ and mixed infection $(0.5 \%)$ and the p.vivax is to be the commonist with the higher incidence $75 \%$ in the month of August and lowest in Feb 51.2\%. Variation in different age groups 14 years and above was observed $25.6 \%$ and mixed infection $0.18 \%$. In the age group 6-14 years $(9.6 \%)$ with mixed infection $(0.05 \%)$ and the lowest prevalence ratio in the age group from 1-5 years $(7.2 \%)$ with mixed infection $0.07 \%$. The table -2 were statistically analysed there is no association between the age groups and types of infection we can say that incidence of any type of infection can happen to any age group person independently.

Keywords: Plasmodium; Plasmodium vivax; Plasmodium falciparum

\section{Introduction}

Globally, malaria is one of the most major health problems particularly in developing countries, Including Pakistan burden of disease is high. The malaria is a vector borne disease caused by plasmodium. There are five spp of malaria includes $P$. falciparum (Plasmodium falciparum), $P$. vivax (Plasmodium vivax), $P$. malariae (Plasmodium malariae), P. ovale (Plasmodium ovale) and P. knowlesi (Plasmodium knowlesi). P. falciparum and $P$. vivax is the common malaria species in Pakistan. Every year 300-500 million cases were reported worldwide with death rate 1.5 to 2.7 million. In the year 2013,627,000 deaths were reported worldwide due to malaria $[1,2]$.

Malaria is endemic in Pakistan. Plasmodium vivax found to be the most common species which can be transmitted by female Anopheles mosquito [3]. Previous data suggests that malaria predominantly occurs in rural areas due to poor drainage system, poor housing and lack of proper sanitation [4].

Malaria is the main health risk in Pakistan and severity of the cases can lead to come and eventually death. There is a plenty of stagnant water after heavy rain in the country, which provides an ideal mosquito breeding environment. In Pakistan malaria 
frequently spread during July to November [5].

A Recent malaria report from Pakistan, published in 2015, evidence sustained decrease in the number of cases. However, we are unable to achieve the global targets of malaria eradication from the world [6].

An epidemiology study was carried in Quetta city reported $36 \%$ cases of cerebral malaria in adults and $64 \%$ cases in children [7].

The incidena of malaria in patients with different age group of rural and urban areas of Quetta showed plasmodium falciparum infection $(16.3 \%, 17.7 \%)$ in 2003 and 2004 respectively [8].

\section{Material and methods}

\section{Study area and sampling}

The study was carried out to find the prevalence rate of malaria among local population of Killa Saifullah district and to assess the spices wise distribution. This study was conducted during $1^{\text {st }}$ June 2016 to 31th May 2017.The inclusive and exclusive were defined.

The patients have temperature, fever, chills, vomiting etc was including in this study. Those patients which do not have general symptoms of malaria were excluded from the current study. The data were collected from different health care centre/Rural health centres, Basic health unit (BHU) and hospitals of the district.

Blood is the only material which is routinely used for the direct detection of malaria parasites in population. Standard WHO recommended methodology were used during this investigation.

Malaria cases are generally detected in Two ways PCD (passive case detection) this is done by examining the blood of patients presenting themselves to a health station with symptoms and sings of malaria or ACD (Active case detection) this is done by making home visits and examining the blood of persons with symptoms, sings or a history suggestive of malaria present or in recent past .

\section{Blood film examination, field and laboratory studies in parasitology}

Seasonal preparation of blood slides, both thick and film were made twice during each month from each resident and Giemsa stained slides were examined in the Lab for parasites.

\section{Identification of malarial parasite}

Prepared thick and thin slides were further examined in the lab for species identification.

\section{A. Preparation of a thin blood film}

A thin blood film was made by a spreading of drop of blood evenly across of a clean grease free slide, using a smooth-edged spreader.

\section{B. Preparation of thick blood film}

Thin smear was used for describing blood cells. The tick smear was used for detecting malarial parasites and microfilariae. A large drop of blood was taken on the centre of a slide and with the aid of a needle or a slide corner spread the drop over $1 / 2$ an inch square area when dry the thickness, should be such that printed matter can be seen through it.

\section{Fixation of blood film}

Before staining, the blood films need to be fixed with acetone free methyl ethyl Alcohol for $1 / 2$ to 1 minute.

\section{Identification of malarial parasites}

The stained blood slides were examined under oil immersion microscope. The thick film shows the presence or absence of malarial parasites in 1 or 2 fields, but in thin films species of parasites can be identified in falciparum malaria, the presence of gametocyte crescent make species identification simple. According to Paniker [9] many tests have been developed, but none can replace the thick and thin smear which alone can reveal the parasite morphology clearly enough for accurate identification of the species. A careful and 
patient smear examination still remains as the 'gold standard' in malaria diagnosis [10]. Plasmodium species identification was made following the keys furnished by [8, 11-13]. $P$. vivax and $P$. falciparum were distinguished by the structure of trophozoites and gametocytes.

\section{Statistical analysis}

Based on the chi-square-test formula mentioned by Neil, WA.1982, the data were statistically analysed to test if there exists any Association between types of infection and age group through a chi-square test formula mentioned below;

$$
x 2 \mathrm{cal} \sum=\frac{\left(f_{0}-f^{\mathrm{e}}\right) 2}{\mathrm{fe}}=6.907
$$

The table value of $t a b=9.488$ if the $X$. cal=6.907 Value is less than the table value, it means that there is no association between types of infection $(P$. vivax and $P$. falciparum) and age group of the patients and malaria infection can happen to any age group person independent ally.

\section{Results}

A total no of 4208 blood smear were prepared from the age groups ranging from 1 year to 5years, 6 to 14 years and 15 years and above residing in different localities of district Killa Saifullah. However, variation was observed among different localities having different hygienic conditions.

In Killa Saifullah district (Table 1), The overall incidence of plasmodium slide positivity was $(20.0 \%)$ where is $P$. vivax was observed to be higher $(64.7 \%)$ as compared with that of $P$. falciparum $(34.7 \%)$ and Mixed infection $(0.7 \%)$.

$P$. vivax was observed with the highest incidence of $(75 \%)$ in the month of August and lowest in the month of Feb (51.2\%).

Table 2 shows variation in different age groups of 14 years and above $(25.6 \%)$ and $(0.18 \%)$ observed mixed infection. In the age group of $06-14$ years $(9.6 \%)$ and mixed infection was $(0.05 \%)$ and lowest prevalence ratio in the age group from 01-05yeasr $(7.2 \%)$ and mixed infection was also observed $(0.07 \%)$.

Table 1. Month wise human malarial infection in district Killa Saifullah

\begin{tabular}{|c|c|c|c|c|c|c|}
\hline S. No. & Month & $\begin{array}{c}\text { No. of } \\
\text { slides } \\
\text { examined }\end{array}$ & $\begin{array}{c}\text { Total No. } \\
\text { of (+ve) }\end{array}$ & P. vivax & $\begin{array}{c}P . \\
\text { Falciparum }\end{array}$ & P. Mix \\
\hline 1 & $\begin{array}{c}\text { June } \\
\text { (2016) }\end{array}$ & 531 & 94 & 61 & 32 & 01 \\
\hline 2 & July & 619 & 101 & 75 & 26 & 00 \\
\hline 3 & August & 691 & 128 & 99 & 29 & 00 \\
\hline 4 & September & 701 & 130 & 80 & 49 & 01 \\
\hline 5 & October & 466 & 98 & 56 & 42 & 00 \\
\hline 6 & November & 276 & 49 & 31 & 16 & 02 \\
\hline 7 & December & 130 & 40 & 23 & 17 & 00 \\
\hline 8 & $\begin{array}{c}\text { January } \\
\text { (2017) }\end{array}$ & 121 & 35 & 25 & 10 & 00 \\
\hline 9 & February & 115 & 41 & 21 & 20 & 00 \\
\hline 10 & March & 101 & 28 & 17 & 11 & 00 \\
\hline 11 & April & 182 & 47 & 28 & 19 & 00 \\
\hline 12 & May & 275 & 51 & 29 & 22 & 00 \\
\hline \multicolumn{2}{|c|}{ Total } & 4208 & $842(20.0 \%)$ & $545(64.7 \%)$ & $297(34.7 \%)$ & $04(0.7 \%)$ \\
\hline
\end{tabular}


$x^{2} \mathrm{cal} \sum=\frac{(f \circ-f e) 2}{f \theta}=6.907$

The table 2 was statistically analyezd to test whether there is any associstion between of infection and age groups through $\chi 2$ at 5\% level of significance $\chi^{2}$ calculated as 6.907 and compared with the tabulated value of tab $=9.488$ since calculated value of $\chi^{2}$ is

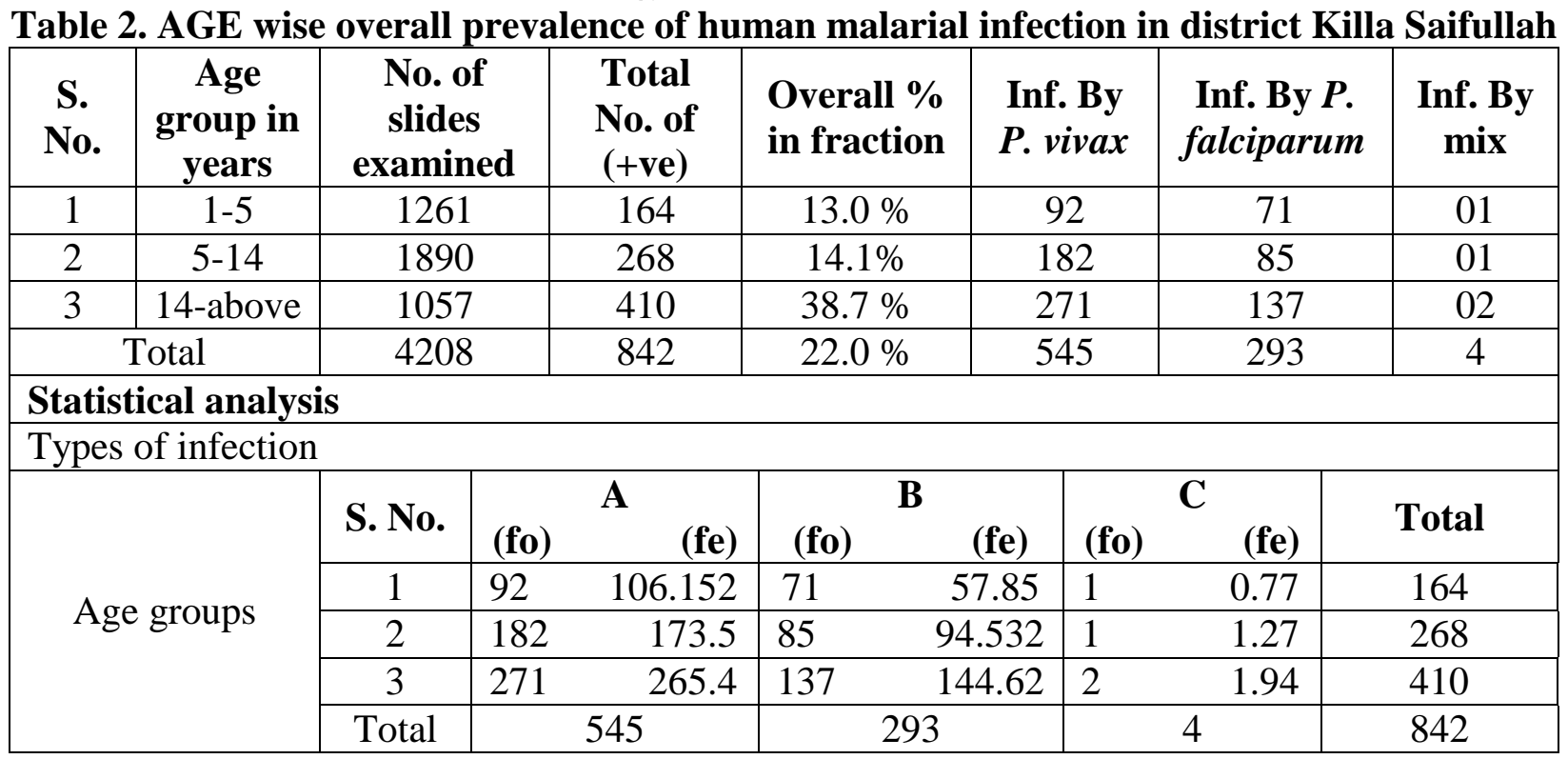

\section{Discussion}

Our result shows that p. vivax to be the commonest spp in the present study with the higher incidence (64.7\%) and the same was observed by malaria control program.

The increased frequency of $P$. vivax was reported in other parts of the country i.e. Okara (98\%), 90.4\% in Muzaffarabad, Multan (60.5\%) and $12.39 \%$ in South Panjab. Elevated rates of $P$. vivax (Plasmodium vivax) was also observed in Ziarat and Kohlu (88.5\% and 58.9\%), ACD and PCD (64.7\% AND 54.6\%) in Ziarat [14].

Regional variation in peak times also occure with the study in the hilly region of Balochistan reporting highest p. vivax infection and lowest falciparum infection in March and the opposite Pattern in October [15]. less than the tabulated value so it is concluded that there is no association between types of infection and age groups. We can say that the incidence of any type of infection can happen to any age group person independently. 


\section{References}

1. World Health Organization (2013).

2. Collins WE (2012). Plasmodium knowlesi; A malaria parasite of monkeys and humans. Annual Review of Entomology 57: 107-21.

3. Khattak AA, Venkatesan MF, Satti HS, Yaqoob A, Strauss K, et al. (2013). Prevalence and distribution of human plasmodium infection in Pakistan. Malaria J 12: 297.

4. World Malaria Report (2014). Geneva, Switzerland: World Health Organization, 32-42. ISBN 978-924156483-0.

5. Khadim, MT (2002) .Malaria a menace at Zhob Garrison. Pakistan Armed Forces Medical Journal 52(2): 203-207.

6. Khan AR, Khan N \& Khan H (2014). Frequency of slide positivity in clinically suspected malaria cases. Gomal J Med Sci 12: 118-20.

7. Durrani, AB, Durrani I, Abbas N \& Jabeen (1997). Epidemiology of cerebral malaria and its mortaility. $J$ Pak Med Assoc 47: 213-215.

8. Yasinzai, MI \& Sulemankhel JK (2003). Incidence of malaria infection in rural areas of District Quetta, Pakistan. On line J Med Sci 3: 766-772.

9. Paniker CKJ (2002). Text Book of Medical Parasitology, $5^{\text {th }}$ Ed Jaypee Brothers, Medical publishers (P) Ltd New Delhi 61-88.

10. Zaman V \& Beg A (2004). Laboratory diagnosis of Malaria. Infect Dis 13: 4748.

11. Cheng Tc (1986). General Parasitology, $2^{\text {nd }}$ Ed. Academic press, Collage Division, New York 1-787.
12. Sood R (1989). Haematology, $3^{\text {rd }} \mathrm{Ed}$, Japee Brothers, Med. Publishers (P), Ltd, New Delhi, India.

13. Chiodini Pl, Moody AH \& Manser DW (2001). Atlas Medical Helminthology and panotology, $4^{\text {th }} \mathrm{Ed}$, Churchill, Livingstone, Edinburgh, London, New York.

14. Mabunda S, Aponte JJ, Tiago A \& Alonso PA (2009). Country-wide malaria survey in Mozambique. Malaria attributable proportion of fever and establishment of malaria case definition in children across different epidemiological settings. Malaria Journal 8:74.

15. Yasinzai MI \& Sulemankhel JK (2008). Incidence of human malaria infection in northern hilly region of Balochistan, adjoining with NWFP, Pakistan: district Zhob. Pak J Biol Sci 11: 1620-1624.

16. Ahmad $\mathrm{T}$, Hussain A \& Ahmad $\mathrm{S}$ (2013). Epidemiology of Malaria in Lal Killa. International $J$ of Scientific and Technology Research 2(1): 199-202.

17. Hussain A, Ahmad T, Ullah N, Jadoon MA \& Zohaib (2014). Epidemiological Approach to Malaria: Plasmodium vivax is common in Lal Qilla (Sub Division), Pakistan. World Applied Sciences J 30(1): 29-31.

18. Soomro FRGM, Bajaj D \& Kakar JK (2010). Malarial Parasites species; Jacobabad District Sindh, Pakistan. Professional Med J 17(3): 440-443.

19. Jamal MM, Jehan A \& Nadir A (2005). Malaria in pediatric age group:a study of 200 cases., Pakistan Armed Forces Med J 55:74-77. 